\title{
A New Approach to Modelling the Drilling Torque in Conventional and Ultrasonic Assisted Deep-Hole Drilling Processes
}

\author{
Ngoc-Hung Chu ${ }^{1, *}$, Dang-Binh Nguyen ${ }^{2}$, Nhu-Khoa Ngo ${ }^{3}$, Van-Du Nguyen ${ }^{3}{ }^{1}$, \\ Minh-Duc Tran ${ }^{3}$, Ngoc-Pi Vu ${ }^{3}{ }^{\circledR}$, Quoc-Huy Ngo $^{3}$ and Thi-Hong Tran ${ }^{4}$ \\ 1 Faculty of International Training, Thai Nguyen University of Technology, $3 / 2$ street, Tichluong ward, \\ Thainguyen City 251750, Vietnam \\ 2 Faculty of Mechanical Engineering, Viet Bac University, 1B street, Dongbam ward, \\ Thainguyen City 252870, Vietnam; nguyendangbinh@vietbac.edu.vn \\ 3 Faculty of Mechanical Engineering, Thai Nguyen University of Technology, 3/2 street, Tichluong ward, \\ Thainguyen City 251750, Vietnam; khoann@tnut.edu.vn (N.-K.N.); vandu@tnut.edu.vn (V.-D.N.); \\ minhduc@tnut.edu.vn (M.-D.T.); vungocpi@tnut.edu.vn (N.-P.V.); ngoquochuy24@gmail.com (Q.-H.N.) \\ 4 Faculty of Mechanical Engineering, Nguyen Tat Thanh University, 300A Nguyen Tat Thanh Street, Ward 13, \\ District 4, Ho Chi Minh City 754000, Vietnam; hongtt.vnuhcm@gmail.com \\ * Correspondence: chungochung@tnut.edu.vn
}

Received: 29 October 2018; Accepted: 20 November 2018; Published: 13 December 2018

check for updates

\section{Featured Application: Deep-hole drilling processes.}

\begin{abstract}
This paper presents a new approach to developing the torque model in deep hole drilling, both for conventional and ultrasonic assisted drilling processes. The model was proposed as a sum of three components: the cutting, the chip evacuation and the stick-slip torques. Parameters of the new model were carried out by applying the regression analysis technique, with the correlation values higher than 0.999 . The data were collected from 36 experimental dry drilling tests, both in conventional and ultrasonic assisted cutting conditions, with the depth-to-diameter of the drilled holes of 7.5. The major advantage of the new model compared to previous models is that the new model of chip-evacuation torque has only one coefficient, thus making it easier to evaluate and compare different deep-drilling processes. The effectiveness of ultrasonic assistance in deep hole drilling was also highlighted using the proposed model. The new model is promising to predict critical depth and torque in deep hole drilling.
\end{abstract}

Keywords: ultrasonic assisted machining; vibration assisted machining; deep drilling; torque; modelling; chip-evacuation

\section{Introduction}

Aluminum alloys have been widely used in applications where materials with high strength-to-weight ratio are required, especially in the rapidly growing automobile and aerospace industries. Although these kinds of materials have good machinability in other cutting operations, they are also considered the most critical materials for drilling [1,2]. Drilling is a preferable machining process, as it takes about one-third of all manufacturing operations [3]. On the one side, dry drilling as well as other dry cutting operations are preferable as environmentally friendly machining techniques. On the other side, it creates greater challenges in the deep drilling of aluminum alloys [4]. During the dry drilling of brittle materials, including aluminum alloys, long and ductile chips tend to bend and coil and thus cause packing of the drill flutes, which interferes with chip ejection [5]. At the deeper 
drilled depth, the increased amount of chips fill up the flutes, leading to chip-clogging, which causes the total torque to increase exponentially [6-11]. The addition of such a chip evacuation torque results in excessive torsional stress, leading to a common failure of the tools known as drill breakage $[8,11,12]$. Whenever the drill broke inside the drilled hole, it was difficult to take out the broken part of the tool from the workpiece, causing catastrophic damage to the parts as well as considerable economic lost [13]. Consequently, chip evacuation has become the main constrain of deep drilling [14]. Specialized drilling tools and techniques have been developed for deep hole drilling, such as the single-lip gun drill, double-tube and single tube drill, boring and trepanning association [15], groove-type chip breaker [16], and peck drilling [12]. Nevertheless, twist drills are still used as a dominant tool, as much as $75 \%$ of the drilling operations in the deep hole drilling industry because of their low cost, versatility, and flexibility [17].

Numerous previous drilling torque models, which are commonly shown in many engineering books, are independent of drilling depth and thus cannot be applied in the practical drilling of deep holes. Therefore, modeling the total torque in deep hole drilling, including the chip evacuation torque, in order to predict the critical drilling depth where the total torque exceeds the allowance torque, becomes a more essential demand for automation and smart machining. Several attempts to model the chip evacuation torque for deep drilling using twist drill bits have been made in recent studies. The very early exponential model was first developed by Mellinger et al. [8] for the drilling of aluminum 356-T6. Sahu et al. [16] evaluated several improvements of chip evacuation criteria in terms of critical depth, chip segmentation, thrust force and torque reduction of groove-type chip breakers on a twist drill. Another model similar to the Mellinger et al. attempt was applied in the drilling of bone for orthopedic surgery [18]. Recently, a practical chip evacuation force model for the deep hole drilling of Al-6061 with three chip evacuation force coefficients was recently developed by Han et al. [14] to avoid difficulties in measuring and experimental calibrations of several parameters in the model proposed by Mellinger et al. Nevertheless, the three coefficient model developed by Han et al. still has difficulties in comparing different drilling processes.

To address this issue, a more practical chip evacuation torque model for deep hole drilling with only one chip evacuation force coefficient is proposed and validated in this study. The new model provides an ability to highlight the effectiveness of a modern technique, which is well known as ultrasonic assisted drilling (UAD). Compared to conventional drilling (CD), UAD has been proved to provide a significant reduction of thrust force [19-23], improvements in built-up edge [19,24], burr size [19,25], tool life, and hole oversize (Amini et al., 2013). A significant reduction of drilling torque of 50\%, when applying UAD for aluminum, has been found in the study of Neugebauer and Stoll [26]. The reduction of cutting force in rotary ultrasonic drilling of ceramic matrix composites with longitudinal-torsional coupled vibration $\mathrm{F}$ was depicted in a recent investigation of Wang et al. [27]. The effectiveness of UAD regarding the reduction of chip evacuation torque, leading to machinability improvement in ultrasonic assisted deep drilling of aluminum alloy 6061, has recently been found in several experimental studies of Nguyen and Chu [28-31]. In this paper, the new approach to modeling the chip evacuation torque is developed, providing a more convenient way to predict drilling torque and to compare the effectiveness of both conventional and ultrasonic assisted deep drilling.

\section{Models of the Drilling Torque}

\subsection{Previous Models}

Typically, the drilling torque model, $T$ is practically expressed in an exponential form as [32]:

$$
T=C \cdot f^{\alpha} \cdot d^{\beta}
$$

where $C, \alpha, \beta$ are constants for particular workpiece material and cutting conditions. The torque is dependent on the drilling diameter, $d$ and the feeding rate, $f$ but independent of the drilling depth. The form of the drilling torque model as shown in Equation (1) can be found in most engineering 
textbooks and handbooks (See [33-35]. It can be useful to predict the drilling torque in normal drilling, where the depth-to-diameter ratio is smaller than 5 [10]. In such kinds of drilling, the chip evacuation force is small and thus can be neglected.

In the torque model for deep hole drilling of Mellinger et al. [8], the drilling torque can be considered as representative of the chip-evacuation performance. In this model, the total drilling torque was considered as a combination of two parts: the cutting torque and the chip-evacuation torque. The cutting torque was considered to be constant and independent of the drilling depth. The chip-evacuation torque increases with the drilling depth as a result of the growing force required to move the cumulative amount of chips that fill the flutes. The chip-evacuation torque, $M$ was expressed in an exponential form as:

$$
M=\frac{R \mu_{w} S_{w} F_{\mathcal{C}}(0)}{B}\left(e^{\left(k B D / A_{0}\right) z}-1\right)
$$

where $R$ and $D$ are the radius and diameter of the drill bit, respectively; $\mu_{w}$ is the friction coefficient between the chips and hole wall; $S_{W}$ is the interface length between the chip and the hole wall; $F_{c}(0)$ is the initial chip-evacuation force when the depth, $z$ is equal to zero; $B$ and $A_{0}$ are the parameters dependent on the workpiece material and other characteristics of the cross section of the chip and the tool flutes as well as the friction force among the chips, the flutes, and the hole wall. The constant coefficient $k$ is a workpeice material property, reflecting the ratio between the lateral and axial pressures from the chip onto the hole wall and the tool flutes.

The Mellinger's model of the chip-evacuation torque was applied in the study of MacAvelia et al. [18] for drilling simulation of bone material in orthopedic surgery. It can be seen that the Mellinger's model includes various parameters, which are difficult to measure or need abundant experimental works to be calibrated. Since the geometrical parameters of a specific drill and the value of each parameter of the model vary with cutting conditions, it is difficult to measure or identify each parameter individually. A recent investigation by Han et al. [14] tried to reduce the number of the parameters of the chip-evacuation torque model. According to the work of Han et al., the chip-evacuation torque, $T_{c h}(z)$ was computed using the following practical model:

$$
T_{c h}(z)=K_{t c h}\left(e^{K_{c h} \cdot z}-1\right) \frac{D}{2}
$$

where $K_{t c h}$ and $K_{c h}$ are coefficients, determined from calibration tests by fitting experimental data, $D$ and $z$ are the tool diameter and the drilled depth, respectively.

This simplified model makes it easier to be practically applied since it consists of only two coefficients, $K_{t c h}$ and $K_{c h}$, which can be experimentally calibrated for particular cutting conditions. However, the two-coefficient model still causes difficulties in comparing several processes. Moreover, all previous models either neglected the fluctuated component in chip-evacuation torque or applied a low pass filter with small threshold frequency to cut off this component, leading to an omission of a substantial part of the total torque. The new model proposed below aims to address these issues.

\subsection{The New Model}

Observing a typical plot of the torque varying in deep drilling as shown in Figure 1, the total torque can be considered as a sum of three components:

$$
T=T_{1}+T_{2}+T_{3}
$$




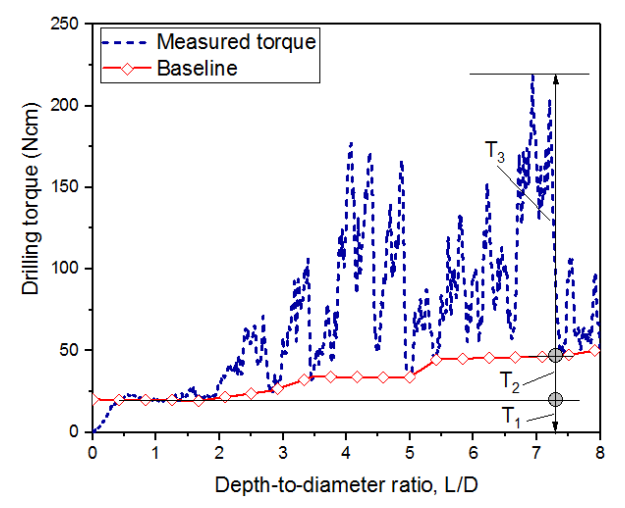

Figure 1. The three components of the drilling torque.

The cutting torque, $T_{1}$ is constant and independent of the drilled depth. $T_{1}$ is determined as the maximum torque when the cutting lips are fully engaged into the workpiece. $T_{2}$ is the component that continuously increases. This torque component is required to evacuate the chips, hereafter named the chip-evacuation torque. The component $T_{3}$ is randomly fluctuated and thus assumed as the torque-t needed to overcome the stick-slip of the chips with the flutes and the hole wall. In this study, $T_{3}$ was named the stick-slip torque.

\subsubsection{The Cutting Torque}

The cutting torque reflects the effort required for chip formation. The practical value of the cutting torque can be taken at the end of the initial rapid increase of the measured torque due to the engagement of the drill point. Previous formula that have commonly appeared in engineering books can be used to model the cutting torque. In this study, the following exponential expression $[32,36,37]$ will be applied and validated:

$$
T_{1}=C \cdot f^{(1-\alpha)} D^{(2-\alpha)}
$$

where the coeficient $C$ can be determined via calibration tests, $\alpha$ is the material factor, which can be taken from handbook data. For aluminum alloys, $\alpha=0.33$ [38]. Here $f$ and $D$ are the feeding rate $(\mathrm{mm} / \mathrm{rev})$ and diameter of the drill bit $(\mathrm{mm})$, respectively. As can be seen in Equation (5), the cutting speed was not included, as the dependence of cutting torque on the drilling speed is typically assumed to be not significant and thus neglected.

\subsubsection{The Chip-Evacuation Torque}

Practical measured data revealed that, the chip-evacuation torque component well satisfies the following expression:

$$
T_{2}=A\left(e^{(A \cdot z)}-1\right)
$$

where $A$ is the only one coefficient of the proposed model and will be determined by calibration tests, $z$ is the drilled depth. Compared to the recent model of Han et al. [14] (See Equation (3)), the new proposed model includes only one coefficient (the constant $A$ ) to be determined, whereas the former required two coefficients of $K_{t c h}$ and $K_{c h}$ to be identified.

The coefficient $A$ can be determined as a function of the cutting parameters and rewritten as a matrix function A using the power law [8,38]:

$$
\begin{gathered}
\ln \mathbf{A}=\mathbf{B}^{*} \mathbf{x} \\
\mathbf{B}=\left[\begin{array}{llll}
a_{0} & a_{1} & a_{2} & a_{3}
\end{array}\right] \\
\mathbf{x}=\left[\begin{array}{llll}
1 & \ln n & \ln f & \ln n \ln f
\end{array}\right]^{\mathrm{T}}
\end{gathered}
$$


where $f$ is the feed rate $(\mathrm{mm} / \mathrm{rev}), n$ is the spindle speed $(\mathrm{rpm}) ; a_{i}(i=0.3)$ are the practical constants determined by the calibration tests.

\subsubsection{The Stick-Slip Torque}

The fluctuated component of the drilling torque, $T_{3}$ can be considered as a result of the stick-slip response of the drilling system, which was apparent in the deep drilling of oil and gas [39,40]. In metal deep drilling, when chips stuck inside the flutes, a cumulative resistant torque occurred and thus required an increase of consumption torque. When the active torque is higher than the resistance, the chips slipped inside the hole wall and resulted in a quick reduction of the torque. The stick-slip component will be analyzed using a statistical technique via the standard Gauss distribution.

\section{Calibration Tests}

\subsection{Experimental Setup}

Figure 2 shows the schema of the experimental setup.



Figure 2. Schema of the experimental tests. 1-Rotary vibration actuator, 2-Lathe chuck, 3-Drill bit, 4-Thermal sensor, 5-Workpiece, 6-fixture, 7-Bearing, 8-Force sensor, 9-Torque sensor, 10-Signal conditioner, 11-DAQ, 12 \& 13-Computer, 14-Ultrasonic power generator, 15-Connector, 16-Lathe carriage.

A universal lathe machine (V-Turn 410) was used for implementing the experimental tests. Workpieces were made in the form of square bars with dimensions of $10 \times 10 \times 30 \mathrm{~mm}^{3}$, made from Al6061-T6. The drilling tests were carried out using standard HSS twist drill bits with a diameter of $4 \mathrm{~mm}$, the point angle of $115^{\circ}$ and the helix angle of $28^{\circ}$, under dry cutting conditions. The drilling torque was measured by a torque sensor model PCB-2508-03A (PCB Piezotronics Company, New York, NY, USA). An ultrasonic generator model MPI WG-3000 WG (MP Interconsulting Company, Neuchatel, Switzerland) was used to convert a $50 \mathrm{~Hz}$ electrical supply to high-frequency electrical impulses. The frequency range of the generator is 20 to $40 \mathrm{kHz}$ and the frequency step is $1 \mathrm{~Hz}$. A photograph of the experimental setup is shown in Figure 3, where elements of the apparatus were numbered the same as in Figure 2. 


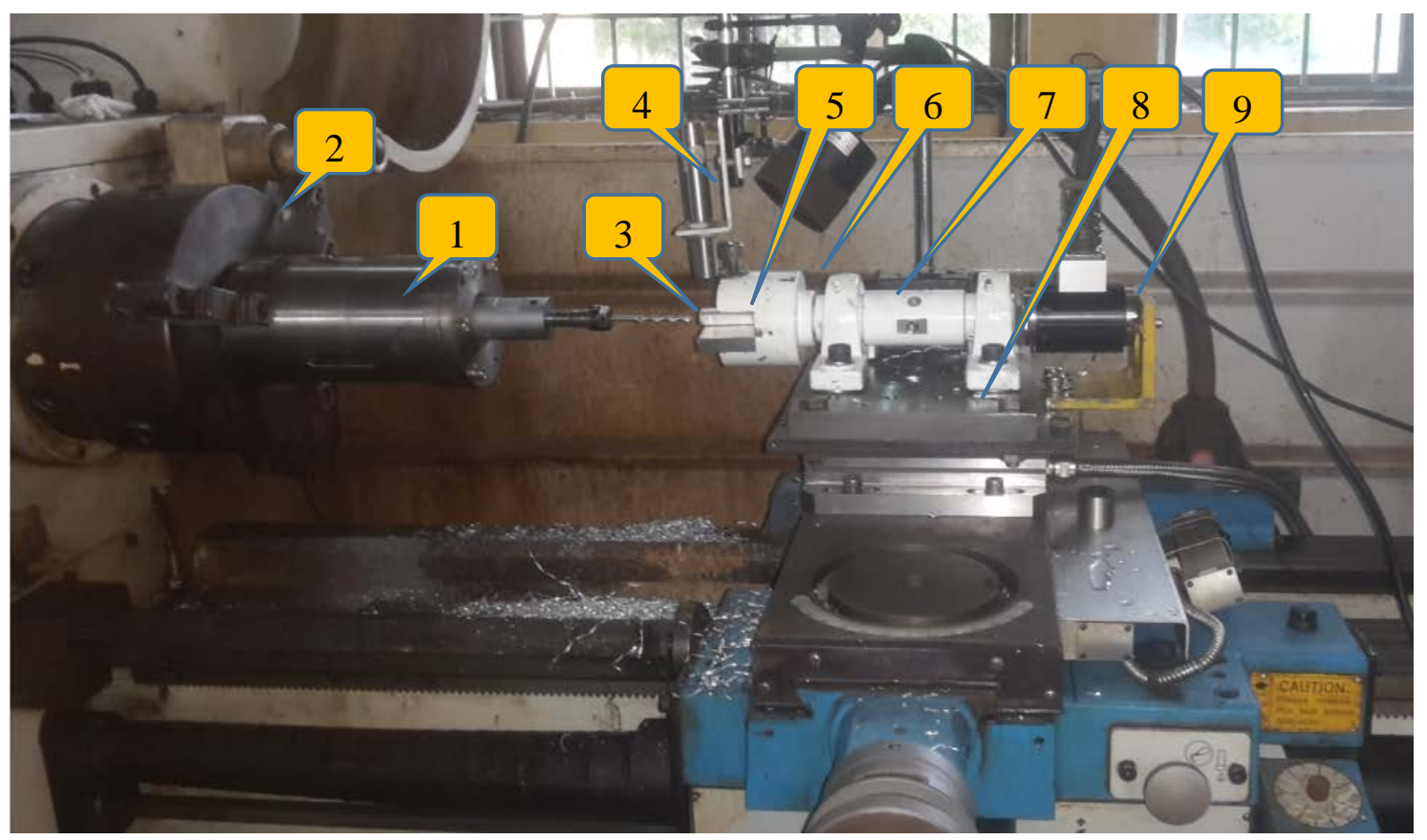

Figure 3. A photo of the experimental tests.

\subsection{Experimental Operations}

Two sets of the calibration tests were implemented separately, one for conventional drilling and another for ultrasonic assisted drilling. In each set, nine experimental tests were planned following a special central composite design named the face-centered plan using two cutting parameters at three levels each, as depicted in Table 1. All experiments were replicated twice to avoid random effects. The experimental parameters are presented in Table 1.

Table 1. Cutting parameters and their levels in experiments.

\begin{tabular}{cccc}
\hline Level & Parameters & Speed (rpm) & Feed Rate $(\mathbf{m m} / \mathbf{r e v})$ \\
\hline $1-3$ & 1000 & 0.050 \\
-1 & 1250 & 0.065 \\
0 & 1500 & 0.085 \\
\hline
\end{tabular}

\section{Results and Discussions}

\subsection{The Cutting Torque}

Experimental data of the cutting torque are depicted in Table 2.

Table 2. Cutting torque $T_{1}$ from conventional drilling (CD) and ultrasonic assisted drilling (UAD) experiments.

\begin{tabular}{|c|c|c|c|c|c|c|c|c|}
\hline$\#$ & $\begin{array}{c}\text { Speed } \\
(\mathrm{rpm})\end{array}$ & $\begin{array}{c}\text { Feed } \\
(\mathrm{mm} / \mathrm{rev})\end{array}$ & $\begin{array}{c}\text { Experimental } \\
T_{1 \_C D} \\
(\mathrm{Ncm})\end{array}$ & $\begin{array}{c}\text { Computed } \\
T_{1 \_C D} \\
(\mathrm{Ncm})\end{array}$ & $\begin{array}{c}\text { Errors } \\
(\%)\end{array}$ & $\begin{array}{c}\text { Experimental } \\
T_{1 \_ \text {UAD }} \\
\text { (Ncm) }\end{array}$ & $\begin{array}{c}\text { Computed } \\
T_{1 \_ \text {UAD }} \\
\text { (Ncm) }\end{array}$ & $\begin{array}{c}\text { Errors } \\
(\%)\end{array}$ \\
\hline 1 & 1000 & 0.05 & 20.513 & 20.769 & -1.247 & 16.549 & 16.717 & -1.017 \\
\hline 2 & 1000 & 0.05 & 20.359 & 20.769 & -2.012 & 15.363 & 16.717 & -8.815 \\
\hline 3 & 1250 & 0.05 & 23.071 & 20.769 & 9.979 & 16.257 & 16.717 & -2.831 \\
\hline 4 & 1250 & 0.05 & 21.562 & 20.769 & 3.679 & 15.995 & 16.717 & -4.516 \\
\hline 5 & 1500 & 0.05 & 22.954 & 20.769 & 9.520 & 17.327 & 16.717 & 3.519 \\
\hline
\end{tabular}


Table 2. Cont.

\begin{tabular}{|c|c|c|c|c|c|c|c|c|}
\hline$\#$ & $\begin{array}{l}\text { Speed } \\
\text { (rpm) }\end{array}$ & $\begin{array}{c}\text { Feed } \\
(\mathrm{mm} / \mathrm{rev})\end{array}$ & $\begin{array}{c}\text { Experimental } \\
T_{1 \_C D} \\
(\mathrm{Ncm})\end{array}$ & $\begin{array}{c}\text { Computed } \\
T_{1 \_C D} \\
\text { (Ncm) }\end{array}$ & $\begin{array}{c}\text { Errors } \\
(\%)\end{array}$ & $\begin{array}{c}\text { Experimental } \\
T_{1 \_U A D} \\
\text { (Ncm) }\end{array}$ & $\begin{array}{c}\text { Computed } \\
T_{1 \_ \text {UAD }} \\
\text { (Ncm) }\end{array}$ & $\begin{array}{c}\text { Errors } \\
(\%)\end{array}$ \\
\hline 6 & 1500 & 0.05 & 21.636 & 20.769 & 4.009 & 16.498 & 16.717 & -1.329 \\
\hline 7 & 1000 & 0.065 & 23.607 & 24.695 & -4.610 & 19.164 & 19.878 & -3.725 \\
\hline 8 & 1000 & 0.065 & 24.442 & 24.695 & -1.036 & 19.941 & 19.878 & 0.317 \\
\hline 9 & 1250 & 0.065 & 25.764 & 24.695 & 4.148 & 21.302 & 19.878 & 6.686 \\
\hline 10 & 1250 & 0.065 & 26.554 & 24.695 & 7.000 & 20.021 & 19.878 & 0.715 \\
\hline 11 & 1500 & 0.065 & 23.523 & 24.695 & -4.983 & 19.405 & 19.878 & -2.437 \\
\hline 12 & 1500 & 0.065 & 27.238 & 24.695 & 9.336 & 20.312 & 19.878 & 2.138 \\
\hline 13 & 1000 & 0.085 & 29.936 & 29.479 & 1.528 & 23.779 & 23.728 & 0.214 \\
\hline 14 & 1000 & 0.085 & 29.779 & 29.479 & 1.009 & 25.674 & 23.728 & 7.579 \\
\hline 15 & 1250 & 0.085 & 30.113 & 29.479 & 2.107 & 24.407 & 23.728 & 2.782 \\
\hline 16 & 1250 & 0.085 & 32.278 & 29.479 & 8.673 & 23.363 & 23.728 & -1.563 \\
\hline 17 & 1500 & 0.085 & 28.484 & 29.479 & -3.492 & 22.404 & 23.728 & -5.910 \\
\hline 18 & 1500 & 0.085 & 28.979 & 29.479 & -1.724 & 24.260 & 23.728 & 2.193 \\
\hline
\end{tabular}

The experimental data of the cutting torque in conventional drilling and ultrasonic assisted drilling were used to calibrate out the coefficient $C$ in the cutting model in Equation (5). The results of regression fitting operations are shown in Table 3. The value of the coefficient $C$ in CD and UAD are about 0.1545 and 0.12516 , with the correlation $R^{2}$ of 0.99869 and 0.99863 , respectively.

Table 3. Calibrated results of the coefficient $C$ in Equation (5).

\begin{tabular}{ccccc}
\hline & Value & Standard Error & Statistics Reduced Chi-Sqr & Statistics Adj. R-Square \\
\hline C_CD & 0.15475 & 0.00199 & 0.000027262 & 0.99869 \\
\hline C_UAD & 0.12156 & 0.0012 & $1.48786 \times 10^{-5}$ & 0.99863 \\
\hline
\end{tabular}

The cutting torque computed by the model described in Equation (5) was then compared to corresponding experimental data. The errors were less than 10 percent, as shown in Table 2.

With the correlation factor higher than 0.99 , it can be said that the model is promising to predict the cutting torque in both conventional- and ultrasonic assisted drilling processes. In other words, the formulas presented in several engineering books are well satisfied to calculate the cutting component in deep hole drilling. Based on the $C$ factor values, UAD provided a cutting torque lower than $C D$, about $0.15475 / 0.12156=1.273$ times. In other words, the effects of ultrasonic assistance can reduce the cutting torque by $27.3 \%$ compared to conventional drilling.

\subsection{The Chip-Evacuation Torque}

The continuous increasing trend of the chip-evacuation torque were taken out by applying a 8-point baseline technique, implemented in OriginLab ${ }^{\circledR} 2017$ software (OriginLab Corporation, Northampton, Massachusetts, USA). The baseline data were then used to carry out the coefficient $A$ of the model in Equation (6). Figure 4 depicts an example of the results. 


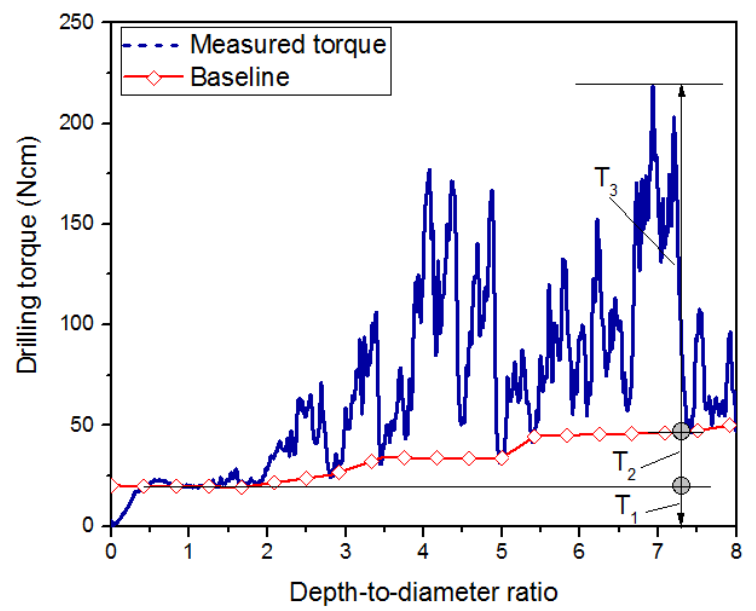

(a)

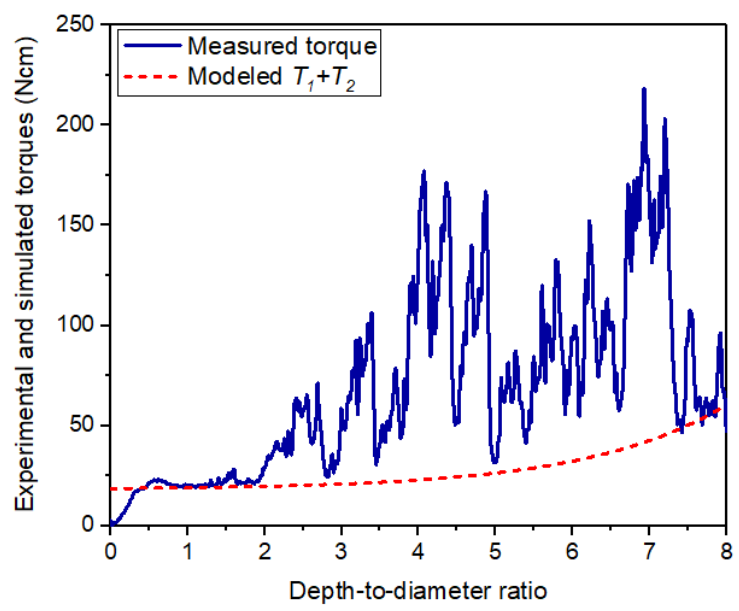

(b)

Figure 4. Example of measured data and (a) its baseline and (b) model torques $T_{1}+T_{2}$.

At first, the baseline of the real measured torque was made, as shown by the red line-diamond in Figure 4a. A regression process was then applied using the model in Equation (6) to calibrate the value of the coefficient $A$. Figure $4 \mathrm{~b}$ shows a result of the processes. Details of the calibration data are listed in Table 4.

Table 4. Cutting torque $T_{1}$ from $C D$ and UAD experiments.

\begin{tabular}{|c|c|c|c|c|c|c|c|c|}
\hline$\#$ & $\begin{array}{l}\text { Speed, } \\
n \text { (rpm) }\end{array}$ & $\begin{array}{c}\text { Feed, } f \\
(\mathrm{~mm} / \mathrm{rev})\end{array}$ & $\begin{array}{l}\text { Coef. } A \\
\text { in CDs }\end{array}$ & $\begin{array}{c}\text { Coef. } A \\
\text { in UADs }\end{array}$ & $\operatorname{Ln}(n)$ & $\operatorname{Ln}(f)$ & $\operatorname{Ln}\left(A_{C D}\right)$ & $\operatorname{Ln}\left(A_{U A D}\right)$ \\
\hline 1 & 1000 & 0.05 & 0.702 & 0.519 & 6.908 & -2.996 & -0.353 & -0.655 \\
\hline 2 & 1000 & 0.05 & 0.679 & 0.507 & 6.908 & -2.996 & -0.387 & -0.679 \\
\hline 3 & 1250 & 0.05 & 0.684 & 0.507 & 6.908 & -2.733 & -0.380 & -0.679 \\
\hline 4 & 1250 & 0.05 & 0.670 & 0.632 & 6.908 & -2.733 & -0.400 & -0.459 \\
\hline 5 & 1500 & 0.05 & 0.623 & 0.536 & 6.908 & -2.465 & -0.473 & -0.624 \\
\hline 6 & 1500 & 0.05 & 0.673 & 0.590 & 6.908 & -2.465 & -0.396 & -0.528 \\
\hline 7 & 1000 & 0.065 & 0.608 & 0.392 & 7.131 & -2.996 & -0.498 & -0.937 \\
\hline 8 & 1000 & 0.065 & 0.633 & 0.546 & 7.131 & -2.996 & -0.457 & -0.604 \\
\hline 9 & 1250 & 0.065 & 0.625 & 0.567 & 7.131 & -2.733 & -0.470 & -0.567 \\
\hline 10 & 1250 & 0.065 & 0.612 & 0.609 & 7.131 & -2.733 & -0.491 & -0.496 \\
\hline 11 & 1500 & 0.065 & 0.658 & 0.470 & 7.131 & -2.465 & -0.418 & -0.754 \\
\hline 12 & 1500 & 0.065 & 0.634 & 0.479 & 7.131 & -2.465 & -0.455 & -0.736 \\
\hline 13 & 1000 & 0.085 & 0.621 & 0.527 & 7.313 & -2.996 & -0.476 & -0.641 \\
\hline 14 & 1000 & 0.085 & 0.659 & 0.533 & 7.313 & -2.996 & -0.416 & -0.629 \\
\hline 15 & 1250 & 0.085 & 0.704 & 0.584 & 7.313 & -2.733 & -0.351 & -0.538 \\
\hline 16 & 1250 & 0.085 & 0.654 & 0.583 & 7.313 & -2.733 & -0.425 & -0.540 \\
\hline 17 & 1500 & 0.085 & 0.641 & 0.516 & 7.313 & -2.465 & -0.445 & -0.662 \\
\hline 18 & 1500 & 0.085 & 0.732 & 0.575 & 7.313 & -2.465 & -0.353 & -0.655 \\
\hline
\end{tabular}

The coefficient $A$ of the chip-evacuation torque model for each hole machined in CD and UAD will be compared in-pair; i.e., in the same cutting parameters. The paired $t$-test is useful for analyzing the same set of data that were obtained under two different conditions, differences between two treatments given to the same subject. In this study, the paired $t$-test was implemented by mean of Minitab ${ }^{\circledR}$ to check the hypothesis declared that the cutting torque in $\mathrm{CD}$ is higher than that in UAD. Using the paired $t$-test, from a limited number of experimental samples, we can predict the difference for the whole population of data. The results of the statistical test are shown in Table 5. 
Table 5. Paired $t$-test for difference of the chip-evacuation coefficient, A between CDs and UADs.

\begin{tabular}{cccccc}
\hline Mean & StDev & SE Mean & 95\% Lower Bound for $\boldsymbol{\mu}$ _difference & $\boldsymbol{t}$-Value & $\boldsymbol{p}$-Value \\
\hline 0.1190 & 0.0580 & 0.0137 & 0.0952 & 2.12 & 0.024 \\
\hline \multicolumn{5}{c}{$\mu$ _difference: mean of (A_CD-A_UAD). }
\end{tabular}

At can be seen from Table 5, with a confident level is of $95 \%$ and the $p$-value less than 0.05 , the coefficient $A$ in the UAD population data is statistically confirmed to be smaller than that in CDs, at least 0.0952 . For the exponential function with only one coefficient (see Equation (6)), the lower the exponential coefficient, the smaller the rate of the function increasing. Hence, at the same cutting conditions and depth $z$, the chip evacuation torque in UAD is smaller than that in CD.

In order to apply the prediction of the chip-evacuation torque at different cutting parameters, the $A$ was expressed as a function of the spindle speed and the feed rate using the power law $[8,38]$, as shown in Equations (7) and (8). The results are depicted in Table 6.

Table 6. Cutting torque $T_{1}$ from $C D$ and UAD experiments.

\begin{tabular}{ccccccc}
\hline & $\mathbf{a}_{\mathbf{0}}$ & $\mathbf{a}_{\mathbf{1}}$ & $\mathbf{a}_{\mathbf{2}}$ & $\mathbf{a}_{\mathbf{3}}$ & Statistics Reduced Chi-Sqr & Statistics Adj. R-Square \\
\hline $\mathrm{CD}$ & -13.7214 & 1.8805 & -4.9359 & 0.6979 & 0.0026 & 0.99995 \\
\hline $\mathrm{UAD}$ & 15.3907 & -2.2047 & 6.0016 & -0.8265 & 0.0141 & 0.99975 \\
\hline
\end{tabular}

The model of the chip-evacuation torque, thus can be summarized as:

$$
\begin{gathered}
T_{2}=A\left(e^{(A \cdot z)}-1\right) \\
\text { forCDs }: \ln \left(A_{C D}\right)=-13.7214+1.8805 \ln (n)-4.9359 \ln (f)+0.6979 \ln (n) \ln (f) \\
\text { forUADs }: \ln \left(A_{U A D}\right)=15.3907-2.2047 \ln (n)+6.0016 \ln (f)-0.8265 \ln (n) \ln (f)
\end{gathered}
$$

Using the approach to develop the model described, one can easily predict the chip evacuation torque for any deep drilling process and thus can determine the ability of the process and the tool to be used.

\subsection{The Stick-Slip Torque}

In metal deep drilling, when the chips were stuck inside the flutes, a cumulative resistant torque occurred and thus required an increase of consumption torque. When the active torque is higher than the resistance, the chips slipped inside the hole wall, and resulted in a quick reduction of the torque. These arbitrary changes can be clearly observed in Figures 4 and 5 a. Since this component is unsystematic, a statistical analysis was applied. The maximum values of $T_{3}$ of each of the investigated tests were taken and then statistically inferred, providing probabilistic distributions of the population data for $T_{3}$ as depicted in Figure $5 \mathrm{~b}$. As can be seen in the Figure, the mean value of the maximum stick-slip torques in UADs was significantly smaller than that in the CDs.

In order to double confirm and quantitatively carry out the effectiveness of ultrasonic assisted drilling over the conventional drilling in the same cutting parameters, a paired $t$-test was made by comparing the $T_{3}$ values in pairs. The average difference, $\mu \_$difference, was calculated as:

$$
\mu \_ \text {difference }=T_{3 \_C D}-T_{3 \_} U A D
$$

Table 7 presents the paired $t$-test results. With a confidence level of $95 \%$ and the $p$-value of 0.012 , it can be said that the stick-slip $T_{3}$ in the UADs tests was smaller than that in CDs. 


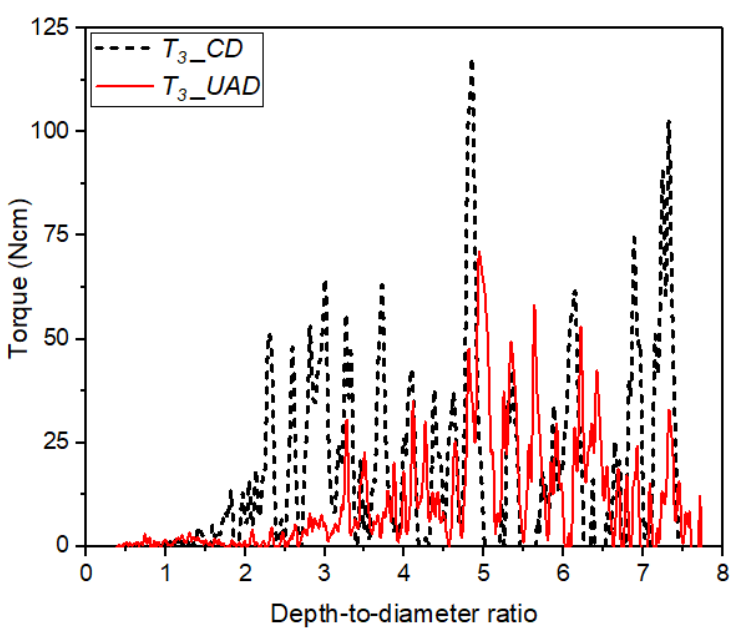

(a)

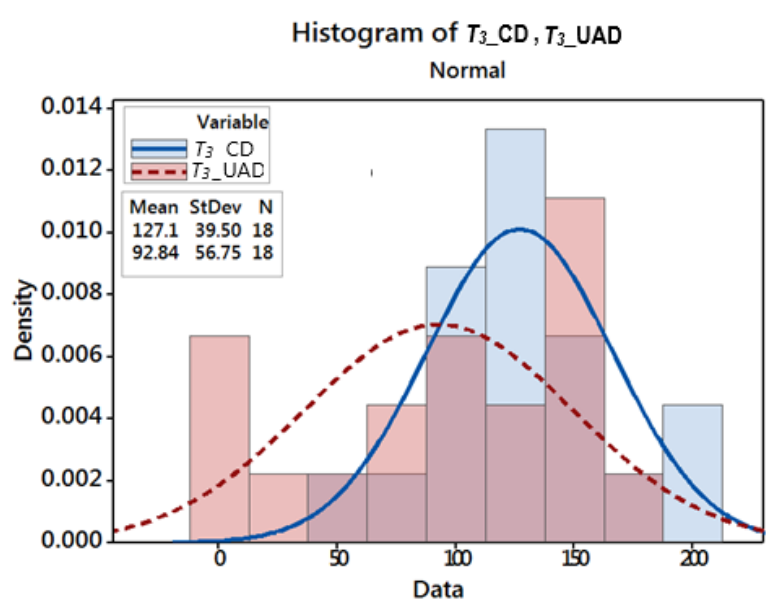

(b)

Figure 5. (a) A couple of conventional drilling (CD) and ultrasonic assisted drilling (UAD) stick-slip torques and (b) probability of the maximum values of stick-slip torques.

Table 7. Estimation for Paired Difference.

\begin{tabular}{|c|c|c|c|c|c|}
\hline Mean & StDev & SE Mean & 95\% CI for $\mu \_$difference & $t$-Value & $p$-Value \\
\hline 34.3 & 51.6 & 12.2 & $(8.6,59.9)$ & 2.82 & 0.012 \\
\hline
\end{tabular}

It can be seen that the maximum values of $T_{3}$ as well as its distribution rule appeared as stochastics factors. Hence, further studies are required to complete the model to predict the stick-slip torque, $T_{3}$.

\section{Conclusions}

This paper implemented a new approach to develop a practical model of drilling torque in deep hole drilling. The new model consists of three components: the cutting, the chip-evacuation, and the stick-slip torques. Remarkable notes are concluded below.

The cutting torque component can be modeled using several drilling torque models, as commonly found in engineering books. Experimental data can fit well with the available model with the regression correlation factor higher than 0.998. It was also revealed that ultrasonic assisted cutting can reduce the cutting torque by $27.3 \%$ in the dry drilling of aluminum alloys.

The chip-evacuation torque can be modeled as an exponential function of the drilling depth with only one coefficient. The coefficient was carried out by experimental calibration with a correlation higher than 0.999 . The only coefficient of the chip-evacuation torque in UADs smaller than that in CDs clearly reflects the improvement of ultrasonic assistance, making the chip evacuation in deep hole drilling easier than conventional drilling.

The stick-slip was scrutinized as a separated component and was considered first in the deep drilling of metals. Further studies should investigate the component model and make it more applicable in practice.

Using the model developed in this study, ones can predict the total torque required in deep hole drilling, either in conventional- or in ultrasonic assisted drilling processes. The model is applicable in other techniques, such as peck drilling, or expandable to other workpiece materials.

Author Contributions: All authors discussed and conceived the original idea. N.-H.C., N.-K.N., Q.-H.N. and V.-D.N. designed and performed experiments. N.-H.C., Q.-H.N. and T.-H.T. analyzed and interpreted experimental data. N.-H.C. wrote the manuscript with support from D.-B.N., M.-D.T., N.-P.V. and V.-D.N. All authors provided critical feedback and helped shape the research, analysis, and manuscript. V.-D.N. supervised this project.

Funding: This research received no external funding.

Conflicts of Interest: The authors declare no conflict of interest. 


\section{References}

1. Zheng, H.; Liu, K. Machinability of Engineering Materials. In Handbook of Manufacturing Engineering and Technology; Nee, A., Ed.; Springer: London, UK, 2013; pp. 1-34.

2. Ashrafi, S.A.; Davoudinejad, A.; Barzani, M.M.; Salehi, P. Investigation into Effect of Tool Wear on Drilling Force and Surface Finish While Dry Drilling Aluminum 2024. Adv. Mater. Res. 2012, 548, 387-392. [CrossRef]

3. Liu, H.S.; Lee, B.Y.; Tarng, Y.S. In-process prediction of corner wear in drilling operations. J. Mater. Process. Technol. 2000, 101, 152-158. [CrossRef]

4. Roy, P.; Sarangi, S.K.; Ghosh, A.; Chattopadhyay, A.K. Machinability study of pure aluminium and Al-12\% Si alloys against uncoated and coated carbide inserts. Int. J. Refract. Met. Hard Mater. 2009, 27, 535-544. [CrossRef]

5. Drozda, T.J. Tool and Manufacturing Engineers Handbook: Machining; Society of Manufacturing Engineers: Dearborn, MI, USA, 1983.

6. Arzur-Bomont, A.; Confente, M.; Schneider, E.; Bomont, O.; Lescalier, C. Machinability in drilling mechanistic approach and new observer development. Int. J. Mater. Form. 2010, 3, 495-498. [CrossRef]

7. Ke, F.; Ni, J.; Stephenson, D.A. Chip thickening in deep-hole drilling. Int. J. Mach. Tools Manuf. 2006, 46, 1500-1507. [CrossRef]

8. Mellinger, J.C.; Ozdoganlar, O.B.; DeVor, R.E.; Kapoor, S.G. Modeling Chip-Evacuation Forces and Prediction of Chip-Clogging in Drilling. J. Manuf. Sci. Eng. 2002, 124, 605-614. [CrossRef]

9. Mellinger, J.C.; Ozdoganlar, O.B.; DeVor, R.E.; Kapoor, S.G. Modeling Chip-Evacuation Forces in Drilling for Various Flute Geometries. J. Manuf. Sci. Eng. 2003, 125, 405-415. [CrossRef]

10. Nagao, T.; Hatamura, Y.; Mitsuishi, M. In-Process Prediction and Prevention of the Breakage of Small Diameter Drills Based on Theoretical Analysis. CIRP Ann. 1994, 43, 85-88. [CrossRef]

11. Furness, R.J.; Ulsoy, A.G.; Wu, C.L. Feed, Speed, and Torque Controllers for Drilling. J. Eng. Ind. 1996, 118, 2-9. [CrossRef]

12. Ravisubramanian, S.; Shunmugam, M.S. Investigations into peck drilling process for large aspect ratio microholes in aluminum 6061-T6. Mater. Manuf. Process. 2017, 33, 935-942. [CrossRef]

13. Choi, Y.J.; Park, M.S.; Chu, C.N. Prediction of drill failure using features extraction in time and frequency domains of feed motor current. Int. J. Mach. Tools Manuf. 2008, 48, 29-39. [CrossRef]

14. Han, C.; Zhang, D.; Luo, M.; Wu, B. Chip evacuation force modelling for deep hole drilling with twist drills. Int. J. Adv. Manuf. Technol. 2018, 98, 3091-3103. [CrossRef]

15. Aized, T.; Amjad, M. Quality improvement of deep-hole drilling process of AISI D2. Int. J. Adv. Manuf. Technol. 2013, 69, 2493-2503. [CrossRef]

16. Sahu, S.K.B.O.; DeVor, O.; Kapoor, R.E.; Shiv, G. Effect of groove-type chip breakers on twist drill performance. Int. J. Mach. Tools Manuf. 2003, 43, 617-627. [CrossRef]

17. Khan, S.A.; Nazir, A.; Mughal, M.P.; Saleem, M.Q.; Hussain, A.; Ghulam, Z. Deep hole drilling of AISI 1045 via high-speed steel twist drills: Evaluation of tool wear and hole quality. Int. J. Adv. Manuf. Technol. 2017, 93, 1115-1125. [CrossRef]

18. MacAvelia, T.; Ghasempoor, A.; Janabi-Sharifi, F. Force and torque modelling of drilling simulation for orthopaedic surgery. Comput. Methods Biomech. Biomed. Eng. 2014, 17, 1285-1294. [CrossRef] [PubMed]

19. Amini, S.; Paktinat, H.; Barani, A.; Tehran, A.F. Vibration Drilling of Al2024-T6. Mater. Manuf. Process. 2013, 28, 476-480. [CrossRef]

20. Azghandi, B.V.; Kadivar, M.A.; Razfar, M.R. An Experimental Study on Cutting Forces in Ultrasonic Assisted Drilling. Procedia CIRP 2016, 46, 563-566. [CrossRef]

21. Chang, S.S.F.; Bone, G.M. Thrust force model for vibration-assisted drilling of aluminum 6061-T6. Int. J. Mach. Tools Manuf. 2009, 49, 1070-1076. [CrossRef]

22. Li, X.; Meadows, A.; Babitsky, V.; Parkin, R. Experimental analysis on autoresonant control of ultrasonically assisted drilling. Mechatronics 2015, 29, 57-66. [CrossRef]

23. Li, X.F.; Dong, Z.G.; Kang, R.K.; Wang, Y.D.; Liu, J.T.; Zhang, Y. Comparison of Thrust Force in Ultrasonic Assisted Drilling and Conventional Drilling of Aluminum Alloy. Mater. Sci. Forum 2016, 861, 38-43. [CrossRef]

24. Barani, A.; Amini, S.; Paktinat, H.; Tehrani, A.F. Built-up edge investigation in vibration drilling of Al2024-T6. Ultrasonics 2014, 54, 1300-1310. [CrossRef] [PubMed] 
25. Chang, S.S.F.; Bone, G.M. Burr height model for vibration assisted drilling of aluminum 6061-T6. Precis. Eng. 2010, 34, 369-375. [CrossRef]

26. Neugebauer, R.; Stoll, A. Ultrasonic application in drilling. J. Mater. Process. Technol. 2004, 149, 633-639. [CrossRef]

27. Wang, J.; Feng, P.; Zhang, J.; Guo, P. Reducing cutting force in rotary ultrasonic drilling of ceramic matrix composites with longitudinal-torsional coupled vibration. Manuf. Lett. 2018, 18, 1-5. [CrossRef]

28. Nguyen, V.-D.; Chu, N.-H. A Study on the Reduction of Chip Evacuation Torque in Ultrasonic Assisted Drilling Of Small and Deep Holes. Int. J. Mech. Eng. Technol. 2018, 9, 899-908.

29. Chu, N.-H.; Nguyen, V.-D.; Do, T.-V. Ultrasonic-Assisted Cutting: A Beneficial Application for Temperature, Torque Reduction, and Cutting Ability Improvement in Deep Drilling of Al-6061. Appl. Sci. 2018, 8, 1708. [CrossRef]

30. Chu, N.-H.; Nguyen, V.-D.; Ngo, Q.H. Machinability enhancements of ultrasonic assisted deep-drilling of aluminum alloys. Mach. Sci. Technol. 2018, in press.

31. Chu, N.-H.; Nguyen, V.-D. The Multi-Response Optimization of Machining Parameters in the Ultrasonic Assisted Deep-Hole Drilling Using Grey-Based Taguchi Method. Int. J. Mech. Prod. Eng. Res. Dev. 2018, 8, 417-426.

32. Juneja, B.L.; Seth, N. Fundamentals of Metal. Cutting and Machine Tools; New Age International Publisher: New Delhi, India, 2003.

33. Carvill, J. 5-Manufacturing technology. In Mechanical Engineer's Data Handbook; Carvill, J., Ed.; Butterworth-Heinemann: Oxford, UK, 1993; pp. 172-217.

34. Smith, G.T. Cutting Tool Technology Industrial Handbook; Springer: London, UK, 2008.

35. Shaw, M.C. Metal Cutting Principles; Oxford University Press, Inc.: New York, NY, USA, 2005.

36. Dandekar, C.; Orady, E.; Mallick, P.K. Drilling Characteristics of an E-Glass Fabric-Reinforced Polypropylene Composite and an Aluminum Alloy: A Comparative Study. J. Manuf. Sci. Eng. 2007, 129, 1080-1087. [CrossRef]

37. Oxford, C.J. On the Drilling of Metals 1-Basic Mechanics of the Process. Trans. ASME 1995, 77, $103-111$.

38. Chandrasekharan, S.G.K.V.; DeVor, R.E. A Mechanistic Model to Predict the Cutting Force System for Arbitrary Drill Point Geometry. J. Manuf. Sci. Eng. 1998, 120, 563-570. [CrossRef]

39. Liu, Y.; Chávez, J.P.; de Sa, R.; Walker, S. Numerical and experimental studies of stick-slip oscillations in drill-strings. Nonlinear Dyn. 2017, 90, 2959-2978. [CrossRef]

40. Zhu, X.; Tang, L.; Yang, Q. A Literature Review of Approaches for Stick-Slip Vibration Suppression in Oilwell Drillstring. Adv. Mech. Eng. 2014, 6, 967952. [CrossRef] 